\title{
Determination of the prebiotic activity of wheat arabinogalactan peptide (AGP) using batch culture fermentation
}

\author{
Suzanne Harris 1,2 (D) Stephen Powers ${ }^{3} \cdot$ Andrea Monteagudo-Mera $^{1} \cdot$ Ondrej Kosik $^{2} \cdot$ Alison Lovegrove $^{2}$. \\ Peter Shewry ${ }^{1,2} \cdot$ Dimitris Charalampopoulos $^{1}$
}

Received: 15 August 2018 / Accepted: 23 January 2019 / Published online: 6 February 2019

(c) The Author(s) 2019

\begin{abstract}
Purpose To test the prebiotic activity of wheat arabinogalactan-peptide (AGP), which is a soluble dietary fibre composed of arabinogalactan polysaccharide linked to a 15-residue peptide, which accounts for up to $0.4 \%$ of the dry weight of wheat flour. Methods The prebiotic activity of AGP prepared from white wheat flour was tested using in vitro fermentation by colonic bacteria in automated $\mathrm{pH}$-controlled anaerobic stirred batch cultures and compared to fructooligosaccharide (FOS) and wheat flour arabinoxylan (AX). Bacterial populations were measured using fluorescence in situ hybridisation (flow-FISH) and short chain fatty acid (SCFA) concentrations were measured using HPLC.

Results Fermentation of AGP resulted in a significant bifidogenic activity and increased concentrations of SCFAs, mainly acetate after $24 \mathrm{~h}$ of fermentation.

Conclusions These results were comparable to those obtained with AX and confirm the prebiotic potential of AGP. Furthermore, fermentation of a mixture of AGP and AX was faster compared to the single substrates and more similar to FOS, indicating that combinations of fermentable carbohydrates with different structures are potentially more effective as prebiotics than single substrates.
\end{abstract}

Keywords Arabinogalactan-peptide (AGP) · Prebiotic · Batch culture $\cdot$ Fluorescence in situ hybridisation (FISH) - Short chain fatty acids (SCFA)

\section{Introduction}

Cereals are the most important source of dietary fibre (DF) in the human diet, providing about $40 \%$ of the total dietary intake in the UK, with bread contributing about half of this.

A number of definitions of dietary fibre have been proposed, the most widely used being that from the Codex

Electronic supplementary material The online version of this article (https://doi.org/10.1007/s00394-019-01908-7) contains supplementary material, which is available to authorized users.

Suzanne Harris

Suzanne.harris@crick.ac.uk

1 Department of Food and Nutritional Sciences, University of Reading, Whiteknights, PO Box 226, Reading RG6 6AP, UK

2 Department of Plant Science, Rothamsted Research, Harpenden, Hertfordshire AL5 2JQ, UK

3 Computational and Analytical Science, Rothamsted Research, Harpenden, Hertfordshire AL5 2JQ, UK
Alimentarius 2009 which states that "dietary fibre consists of carbohydrate polymers with 10 or more monomeric units, which are not hydrolysed by the endogenous enzymes in the small intestine". However, a footnote allows national authorities to also include "carbohydrates of 3-9 monomeric units" and these are usually included when considering wheat fibre. A number of studies have demonstrated that DF, and particularly cereal DF, has health benefits including regulation of satiety and diluting the energy density of food. The addition of insoluble DF to the diet increases stool weight from fibre bulk and increases in bacteria and water holding capacity. Soluble DF has also been shown to reduce the glycaemic index of food products, reduce insulin sensitivity and decrease cholesterol absorption. Furthermore, DF has also been shown to reduce the risk of colorectal cancer.

While whole wheat grain contains $11.5-15.5 \%$ total $\mathrm{DF}$, the content is much lower in the white flour which is used to make most food products and comprises the starchy endosperm, but not the fibre-rich aleurone and outer layers of the grain. The major DF components in 
wheat are cell wall polysaccharides, which account for about $2-3 \%$ of the dry weight comprising about $70 \%$ arabinoxylan (AX), $20 \%(1 \rightarrow 3,1 \rightarrow 4)-\beta$-D-glucan ( $\beta$-glucan), $2 \%$ cellulose $((1 \rightarrow 4)-\beta$-D-glucan $)$ and $7 \%$ glucomannan [1] and 1.4-1.7\% fructo-oligosaccharides (fructans) [2]. In addition, white wheat flour contains up to $0.4 \%$ dry weight of arabinogalactan-peptide (AGP) [3, 4] which comprises a 15-residue amino acid peptide [5] including three hydroxyprolines which are $o$-glycosylated with branched arabinogalactan chains [6]. In most plants, arabinogalactans occur in covalent association with protein, either as proteoglycans or as glycoproteins, however, in wheat AGP, the polysaccharide is estimated to account for about $90 \%$ of the molecular mass. Although a recent study indicates that AGP is located in the cytoplasm or vacuole of the wheat cell, it does not appear to be essential for grain development and little is known of its biological function [7] or impact on human nutrition and health.

The process of fermentation, where colonic microbiota break down carbohydrates to monosaccharides before metabolising them to short chain fatty acids (SCFAs) appears to be particularly important to health benefits of DF. These benefits have led to the concept of "prebiotics": substrates that are selectively utilized by host microorganisms conferring a health benefit [8]. Prebiotics can also alter the host colonic microbiota to a more favourable composition, for example, by increasing the proportions of beneficial bacteria (e.g., bifidobacteria and/or lactobacilli) [9].

Cereal DF components, particularly $\beta$-glucan and fructans, have well-established prebiotic activity, while a number of studies have demonstrated prebiotic activity for wheat AX [10-13]. However, although the concentration of AGP in wheat flour is similar to those of water-soluble AX and total $\beta$-glucan, its prebiotic potential has not been determined. We have, therefore, evaluated the prebiotic properties of AGP and determined whether AGP behaves synergistically with soluble AX from wheat flour, using an in vitro faecal culture system.

\section{Materials and methods}

\section{Materials}

AGP and water-soluble AX [average DP 131 (obtained using HP-SEC-MALLS using OHpak SB 802.5 HQ column on an Agilent 1260 infinity LC system)] were prepared from white flour from the wheat cultivar Yumai 34 using the method from Loosveld et al. [3] Fructo-oligosaccharides (FOS) from chicory (F8052 Sigma) (average DP 2-8) was used as a standard.

\section{Monosaccharide analysis}

Fifty $\mu \mathrm{L}$ of a solution of $1 \mathrm{mg} / \mathrm{mL}$ AX was dried under vacuum to which was added $400 \mu \mathrm{L}$ of $2 \mathrm{M}$ trifluoroacetic acid (TFA) and incubated at $120^{\circ} \mathrm{C}$ for $1 \mathrm{~h}$ in a heating block to hydrolyse samples. Hydrolysed samples were cooled on ice and dried in speed-vac at $30^{\circ} \mathrm{C}$ (overnight). $500 \mu \mathrm{L}$ of water was added to remove any remaining TFA and the sample was dried again in the speed-vac. The sample was finally resuspended in $400 \mu \mathrm{L}$ of MilliQ water. The hydrolysate was diluted further 1:1 with water. Standard curves were constructed for fucose, rhamnose, arabinose, galactose, glucose, xylose, mannose, galacturonic acid, and glucuronic acid using monosaccharide standards prepared from stock solutions of $1 \mathrm{mM}$ and subjecting them to the same acidhydrolysis protocol as for samples. All samples and standards were run under the same conditions as described below. Twenty $\mu \mathrm{L}$ was injected onto a Carbopac PA20 column with flow rate $0.5 \mathrm{~mL} / \mathrm{min}$ and gradient: isocratic $4.5 \mathrm{mM} \mathrm{KOH}$, 0-13 min; linear 4.5 to $10 \mathrm{mM} \mathrm{KOH,} \mathrm{13-14} \mathrm{min;} \mathrm{linear} 10$ to $13 \mathrm{mM} \mathrm{KOH}, 14-15 \mathrm{~min}$; linear 13 to $20 \mathrm{mM}, 15-16 \mathrm{~min}$; isocratic $20 \mathrm{mM} 16-17 \mathrm{~min}$; linear 20 to $4.5 \mathrm{mM} \mathrm{KOH}$, 17-18 min followed by isocratic 4.5 mM KOH 18-23 min; on a Dionex 5000 Ion Chromatography HPLC equipped with disposable gold electrode.

\section{MALDI-ToF-MS}

MALDI-ToF-MS was as described in Marsh et al. [14] using a Micromass MALDI-LR mass spectrometer (Waters, Manchester, UK).

\section{In vitro fermentation}

$100-\mathrm{mL}$ sterile batch fermentation vessels $(50 \mathrm{~mL}$ working volume) were aseptically filled with $45 \mathrm{~mL}$ of sterile basal medium and sparged with $\mathrm{O}_{2}$ - free $\mathrm{N}_{2}$ overnight to establish anaerobic conditions. The medium contained per litre: $2 \mathrm{~g}$ of peptone water (Oxoid Ltd., Basingstoke, UK), $2 \mathrm{~g}$ of yeast extract (Oxoid), $0.1 \mathrm{~g}$ of NaCl, $0.04 \mathrm{~g}$ of $\mathrm{K}_{2} \mathrm{HPO}_{4}, 0.01 \mathrm{~g}$ of $\mathrm{MgSO}_{4} \cdot 7 \mathrm{H}_{2} \mathrm{O}, 0.01 \mathrm{~g}$ of $\mathrm{CaCl}_{2} \cdot 6 \mathrm{H}_{2} \mathrm{O}, 2 \mathrm{~g}$ of $\mathrm{NaHCO}_{3}$, $0.005 \mathrm{~g}$ of hemin (Sigma), $0.5 \mathrm{~g}$ of l-cysteine $\mathrm{HCl}$ (Sigma), $0.5 \mathrm{~g}$ of bile salts (Oxoid), $2 \mathrm{~mL}$ of Tween $80,10 \mu \mathrm{L}$ of vitamin K (Sigma). Polysaccharide samples were added $(1 \% \mathrm{w} / \mathrm{v})$ to the basal medium. Each vessel was inoculated with $10 \%(\mathrm{v} / \mathrm{v})$ of faecal slurry from a single donor, which was prepared by homogenizing fresh human faeces $(10 \%$, $\mathrm{w} / \mathrm{w}$ ) in phosphate-buffered saline (PBS; $8 \mathrm{~g} / \mathrm{L} \mathrm{NaCl}, 0.2 \mathrm{~g} / \mathrm{L}$ $\mathrm{KCl}, 1.15 \mathrm{~g} / \mathrm{L} \mathrm{Na}_{2} \mathrm{HPO}_{4}$, and $0.2 \mathrm{~g} / \mathrm{L} \mathrm{KH}_{2} \mathrm{HPO}_{4}$ ), $\mathrm{pH} 7.3$ (Oxoid), using a stomacher (Stomacher 400, Seward). Three non-pooled faecal donors were used per experiment, two 
male and one female, between 23 and 59 years of age and on a normal diet without any special dietary requirements and that had not taken antibiotics, prebiotic or probiotics in the previous 3 months. Two experiments were run due to limitations of vessel numbers, one with a negative control (no carbon source added), FOS ( $0.5 \mathrm{~g}$ ) (positive control), AGP $(0.5 \mathrm{~g})$ and $\mathrm{AGP}+\mathrm{AX}(0.25 \mathrm{~g}$ and $0.25 \mathrm{~g})$, and the second with a negative control, positive control as before and AX $(0.5 \mathrm{~g})$. Vessels were incubated at $37^{\circ} \mathrm{C}$ with a water jacket for up to $48 \mathrm{~h}$ and the $\mathrm{pH}$ was controlled between 6.7 and 6.9 using an automated $\mathrm{pH}$ controller with $0.5 \mathrm{M} \mathrm{HCL}$ and $\mathrm{NaOH}$ (Fermac 260, Electrolab, Tewkesbury, UK). Samples $2 \times 1 \mathrm{~mL}$ were collected at 0,8 and $24 \mathrm{~h}$ for analysis.

\section{SCFA analysis using HPLC}

Aliquots of $750 \mu \mathrm{L}$ were removed from in vitro fermentation vessels and centrifuged at $13,000 \times g$ for $5 \mathrm{~min}$ to remove particulate matter and filtered using a $0.2 \mu \mathrm{M}$ nitrocellulose filter. $20 \mu \mathrm{L}$ was injected on to a Rezex ROA Organic Acid $\mathrm{H}^{+}(8 \%)$ HPLC column (Phenomenex, UK) at $50{ }^{\circ} \mathrm{C}$ on a Shimadzu Prominence HPLC with $0.0025 \mathrm{M} \mathrm{H}_{2} \mathrm{SO}_{4}$ eluent at a flow rate of $0.6 \mathrm{~mL} / \mathrm{min}$. SCFA (lactate, formate acetate, propionate and butyrate) were quantified with reference to calibration curves from 5 to $50 \mathrm{mM}$ of authentic standards (Sigma).

\section{Enumeration of bacteria by flow-FISH}

Samples of $750 \mu \mathrm{L}$ removed from in vitro fermentation vessels were immediately placed on ice, before centrifugation at $13,000 \times g$ for $3 \mathrm{~min}$ and the supernatant discarded. Pelleted bacteria were fixed for $4 \mathrm{~h}$ at $4{ }^{\circ} \mathrm{C}$ in (PBS) and $4 \%(\mathrm{w} / \mathrm{v})$ filtered paraformaldehyde (PFA) (Sigma-Aldrich P6148, $\mathrm{pH} 7.2)$ in a ratio of $1: 3(\mathrm{v} / \mathrm{v})$. Samples were washed twice with filtered PBS and resuspended in $600 \mu \mathrm{L}$ of a mixture of PBS/ethanol $(1: 1, \mathrm{v} / \mathrm{v})$ and then stored at $-20{ }^{\circ} \mathrm{C}$ for up to 3 months. Hybridisation was carried out as described in Rycroft et al. [15, 16] using genus and group specific 16S rRNA-targeted oligonucleotide probes (MWG Biotech, Ebersberg, Germany).

The sample probes used were Bif164 [17], Bac303 [18], Lab158 [19], Ato291 [20], Prop853 [21], Erec482 [22], Rrec584 [21], Fprau655 [23], Chis150 [22], shown in Supplementary Table 1 . Samples were screened using a flow cytometer (Accuri C6, BD Biosciences, USA) with Accuri CFlow software.

\section{Statistical analysis}

The Genstat (2015, 18th edition, (c) VSN International Ltd, Hemel Hempstead, UK) statistical package was used for all analysis. One-way analysis of variance (ANOVA) and $F$ test were applied to determine differences between treatments. Differences were deemed significant when $P<0.05$.

\section{Results}

\section{Monosaccharide analysis}

Monosaccharide analysis of the AGP prepared from white flour (Triticum aestivum cv. Yumai 34) indicated that arabinose and galactose together comprised $96.73 \%( \pm 0.18)$ of total monosaccharides, with small amounts of glucose (2.6\%) and xylose $(1.74 \%)$. The A: G ratio for AGP was 0.48 . The combined contents of arabinose and xylose in the arabinoxylan fraction prepared from the same flour were $91 \%( \pm 0.05)$, with galactose $(5 \%)$ and glucose $(4 \%)$. The $\mathrm{A}: \mathrm{X}$ ratio for $\mathrm{AX}$ was 0.62 . These data indicate that the AGP and AX fractions were over $95 \%$ and over $90 \%$ pure, respectively.

MALDI-TOF-MS was used to confirm the structure and purity of the carbohydrate moiety of the AGP, based on the molecular masses of the oligosaccharides released by the exo-b- $(1 \rightarrow 3)$-galactanase. All samples were permethylated as described in Tryfona et al. [6] based on Ciucanu and Kerek [24] prior to mass spectrometry. Figure 1 shows the spectrum from 400 to $2400 \mathrm{~m} / z$; the oligosaccharide composition is indicated by Hex (hexose residues) or Pent (pentose residues) while the subscript indicates the number of residues present, if greater than 1 . The dominant ion was ' $\mathrm{Hex}_{2}$ Pent', at $637.5 \mathrm{~m} / \mathrm{z}$ which is predicted to be two galactose units and an arabinose unit. The other ions are predicted as follows: $m / z$ 477.7, $\mathrm{Hex}_{2} ; 841.5$, $\mathrm{Hex}_{3} \mathrm{Pent}$; 1001.6, Hex $_{3}$ Pent $_{2} ; 1161.6$, Hex $_{3}$ Pent $_{3} ;$ 1365.8, Hex $_{4}$ Pent $_{3} ; 1730.0$, Hex $_{5}$ Pent $_{4} ;$ 1934.0, Hex 6 Pent 4 ; 2095.2, Hex 6 Pent ${ }_{5}$.

\section{Effect of fermentation on SCFA concentrations}

The concentrations of SCFA and lactate after fermentation of AGP were compared with the negative control (no substrate), FOS (positive control) and AX in Table 1. Significant increases $(p<0.05)$ compared to the negative control, occurred in the concentrations of total SCFAs for all substrates, which mainly resulted from increased acetic acid. Acetic acid concentrations increased after $8 \mathrm{~h}$ fermentation of all substrates, with FOS having the greatest increase. Acetate continued to increase until $24 \mathrm{~h}$ fermentation for all substrates, however, at $24 \mathrm{~h}$ the greatest increase in acetate was by fermentation of AGP (39.34 mM) and AGP + AX (38.91 mM). Large decreases occurred in lactate concentrations with the AGP, AGP + AX and AX substrates after $24 \mathrm{~h}$ compared with their negative controls. Total SCFA concentrations after $24 \mathrm{~h}$ fermentation were all significant and similar, the highest being with FOS $(72.36 \mathrm{mM})$, then in 
Fig. 1 Monosaccharide analysis of extracted AGP and AX using a Carbopac PA20 column $(N=3)$. Error bars are SD

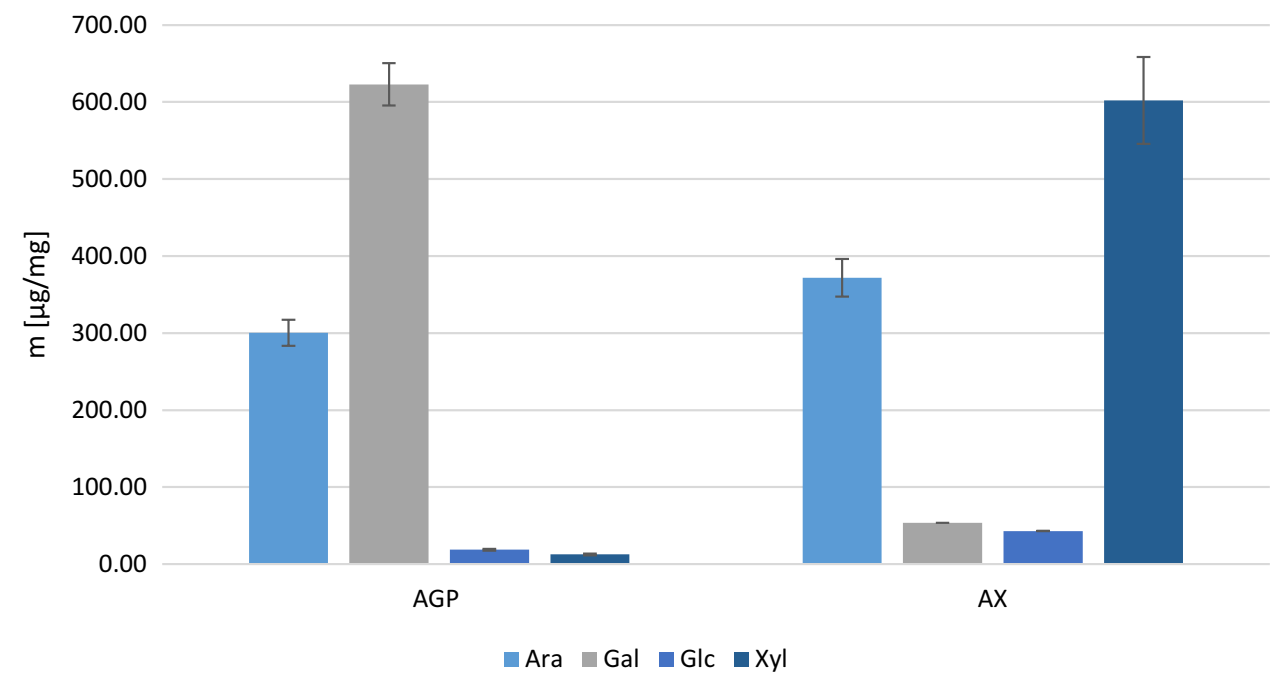

Table 1 SCFA and lactate concentration in batch cultures at $0,4,8$ and 24 h fermentation comparing no substrate, FOS, AGP and AX

\begin{tabular}{lrrrrll}
\hline & \multicolumn{1}{l}{ Time } & \multicolumn{1}{l}{ Lactate } & \multicolumn{1}{l}{ Acetate } & Propionate & Butyrate & Total \\
\hline Negative control & 0 & $2.28(1.20)$ & $3.13(1.05)$ & $3.52(0.62)$ & $2.86(1.08)$ & $21.61(1.48)$ \\
& 8 & $6.30(1.79)$ & $8.31(1.84)$ & $5.10(0.97)$ & $1.57(0.65)$ & $27.12(5.41)$ \\
FOS & 24 & $10.17(2.42)$ & $8.28(2.04)$ & $10.25(5.19)$ & $3.32(1.24)$ & $36.33(8.49)$ \\
& 0 & $7.22(3.51)$ & $9.16(1.09)$ & $5.27(1.80)$ & $2.33(0.28)$ & $27.55(8.28)$ \\
& 8 & $12.61(8.95)$ & $30.57(4.77)^{*}$ & $11.27(5.59)$ & $3.09(1.98)$ & $67.45(17.12)^{*}$ \\
AGP & 24 & $10.16(5.53)$ & $33.35(6.69)^{*}$ & $13.03(7.03)$ & $8.36(6.59)$ & $72.36(32.92)^{*}$ \\
& 0 & $7.86(5.12)$ & $6.80(3.25)$ & $3.49(1.52)$ & $5.78(1.67)$ & $25.54(5.97)$ \\
AGP+AX & 8 & $5.75(2.37)$ & $23.83(5.95)^{*}$ & $12.33(5.09)$ & $2.81(1.07)$ & $50.96(11.40)^{*}$ \\
& 24 & $3.48(1.65)^{*}$ & $39.34(4.53)^{*}$ & $8.60(6.90)$ & $5.20(3.53)$ & $61.95(9.94)^{*}$ \\
Negative control for AX & 0 & $10.01(2.58)$ & $6.95(3.49)$ & $5.48(1.37)$ & $3.53(0.84)$ & $36.92(9.28)$ \\
& 8 & $4.50(1.98)$ & $17.05(8.52)$ & $12.86(5.25)$ & $2.37(1.94)$ & $44.08(15.81)$ \\
& 24 & $2.38(1.03)^{*}$ & $38.91(9.58)^{*}$ & $15.61(6.47)$ & $2.95(1.74)$ & $67.42(10.47)^{*}$ \\
AX & $11.02(3.68)$ & $4.21(1.22)$ & $4.36(1.11)$ & $2.22(0.50)$ & $21.85(3.15)$ \\
& $5.66(0.44)$ & $9.05(2.40)$ & $8.77(1.42)$ & $1.53(0.36)$ & $26.24(3.97)$ \\
& 24 & $6.45(0.16)$ & $9.84(2.71)$ & $9.33(1.85)$ & $1.20(0.22)$ & $30.08(1.97)$ \\
& 0 & $16.39(3.37)$ & $4.93(1.01)$ & $5.05(0.60)$ & $1.54(0.20)$ & $27.91(3.04)$ \\
& 8 & $10.19(2.86)$ & $21.12(4.46)^{*}$ & $8.09(0.48)$ & $1.76(1.76)$ & $47.79(4.99)^{*}$ \\
& 24 & $2.56(1.31)^{*}$ & $27.64(4.85)^{*}$ & $9.76(2.77)$ & $1.29(0.12)$ & $57.15(12.25)^{*}$ \\
\hline
\end{tabular}

Formate is included in total SCFA but not shown. One-way AVONA was applied to the data to test the main interaction between treatments. Significant interaction between treatments and negative control are denoted. Standard error of the mean (SEM) is shown in brackets. Significant differences between treatments and relevant negative control are denoted $* p=0.05$ ( $F$ test) order of decreasing concentration, AGP + AX (67.42 mM), AGP (61.95 mM) and AX (57.15 mM). Although the 1:1 mixture of AX and AGP resulted in higher concentrations of total SCFAs than either single substrate, these increases were not statistically different.

\section{Effect of fermentation on bacterial populations}

The populations of the dominant types of human colonic bacteria are shown in Table 2, while the populations of total enumerated bacteria, Bifidobacterium and Clostridium
coccoides/Eubacterium rectale are shown in Fig. 2. The Bifidobacterium populations increased significantly $(p<0.05)$ compared to the negative control after $8 \mathrm{~h}$ fermentation for FOS (positive control) and AGP + AX with the greatest increase of $1.95 \log$ occurring with fermentation of FOS, followed by an increase of $1.37 \log$ with $\mathrm{AGP}+\mathrm{AX}$. The populations of Bifidobacterium increased with the separate AX and AGP substrates between 8 and $24 \mathrm{~h}$, but decreased 0.88 $\log$ between 8 and $24 \mathrm{~h}$ for FOS and $0.53 \log$ for AGP + AX. As with Bifidobacterium, the Clostridium coccoides-Eubacterium rectale group increased after $8 \mathrm{~h}$ fermentation of FOS 


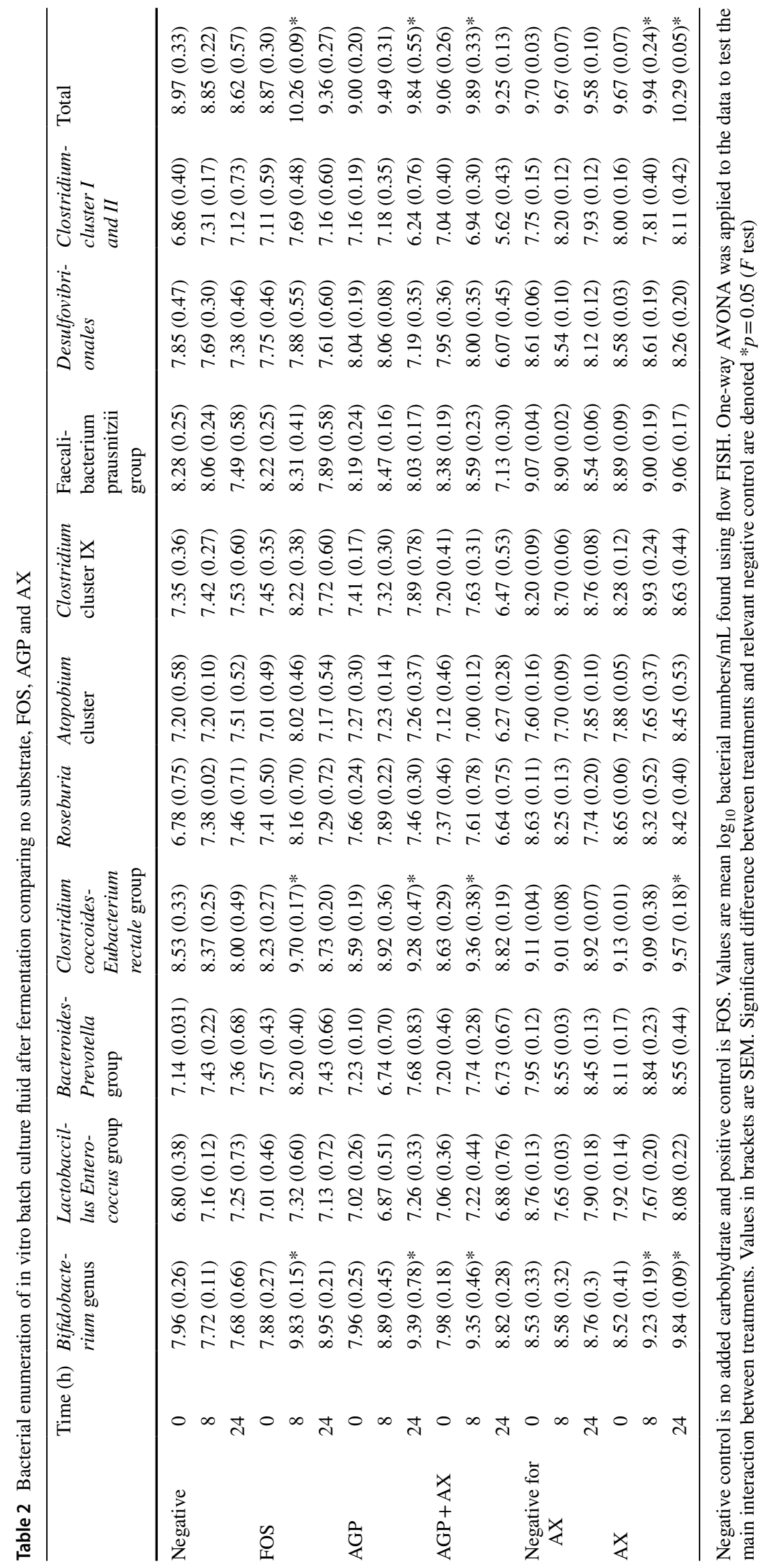




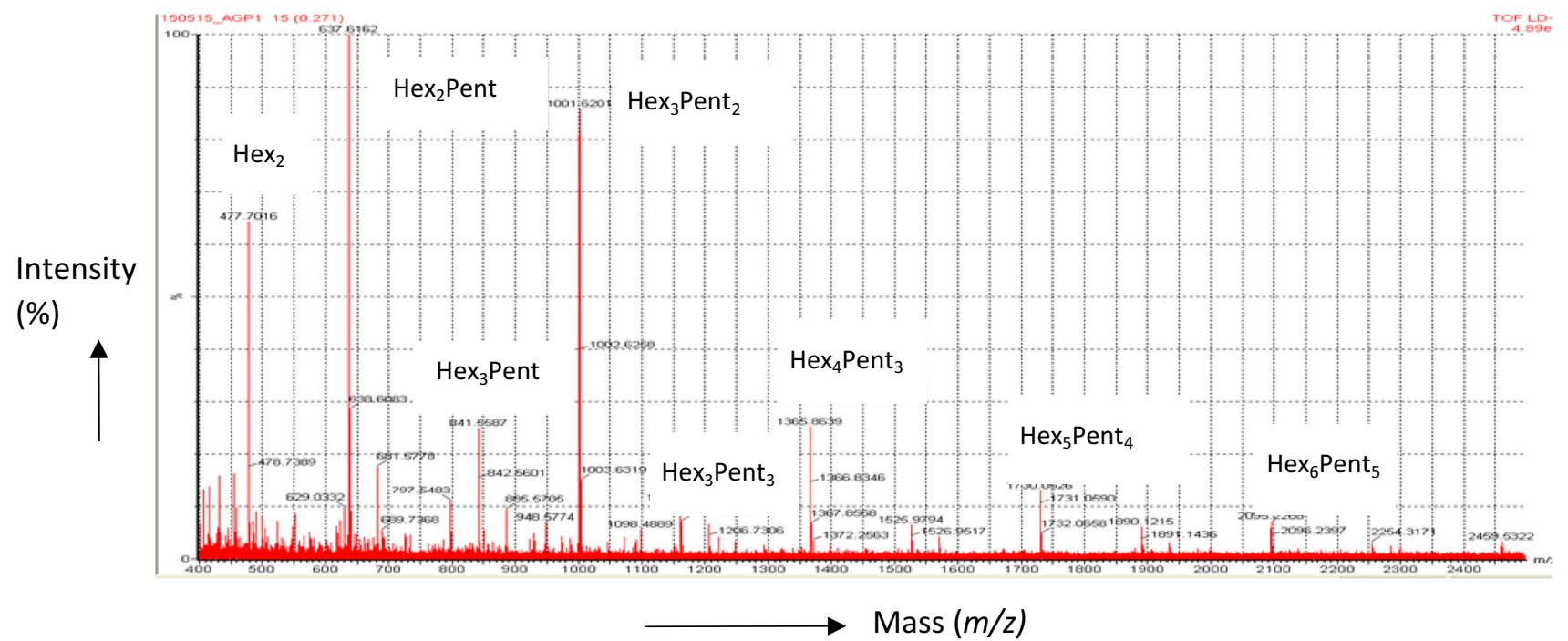

Fig. 2 MALDI-ToF-MS spectra showing ions of $\mathrm{m} / \mathrm{z}$ diagnostic of per-methylated oligosaccharides released from AGP by exo-B-(1 $\rightarrow 3)$ galactanase digestion. AGP was isolated from Triticum aestivum cv. Yumai-34 white flour. Spectra shows 400-2400 m/z

and $\mathrm{AGP}+\mathrm{AX}$, and after $24 \mathrm{~h}$ fermentation of AX and AGP. No significant changes were observed in the Lactobacillus Enterococcus group, Bacteroides-Prevotella group, Roseburia, Atopobium, Desulfovibrionales, Clostridium cluster IX, Faecalibacterium prausnitzii group or Clostridium-cluster I and II. The 1:1 mixture of AGP and AX gave significantly greater populations of the beneficial Bifidobacterium and Clostridium coccoides/Eubacterium rectale groups than either single substrate at $8 \mathrm{~h}$, but these were lower at $24 \mathrm{~h}$.

\section{Discussion}

This study aimed to determine the prebiotic potential of the soluble wheat fibre AGP. AGP isolated from wheat flour was characterised and evaluated for prebiotic activity based on increases in the populations of beneficial bacteria and in the production of SCFA, using in vitro batch cultures. The fermentation of AGP was also compared to FOS and AX, which have established prebiotic activity [10, 11, 25, 26], in addition, a mixture of AGP and AX was tested to determine whether the combination may result in a synergistic prebiotic effect.

Short chain fatty acids (SCFA) are volatile fatty acids consisting of a straight-chain, aliphatic tail of fewer than six carbon atoms and are produced by fermentation of oligosaccharide concomitant with increases in beneficial bacteria including Bifidobacterium. The principal SCFAs are acetate, propionate and butyrate, together comprising $95 \%$ of all SCFAs produced [27] and are metabolized primarily by the colonic epithelium (butyrate), liver (propionate) and muscle (acetate) [28]. The concentrations of SCFAs in this study were used as a measure of the rate of fermentation of the substrates, with significant increases particularly apparent in the predominant SCFA, acetate. The spectra in Fig. 2 are very similar to those reported for AGP from white flour of cv. Cadenza by Tryfona et al. [6]. The mass spectra, therefore, confirm the purity and identity of the AGP used for in vitro fermentation.

Despite the huge variety of different bacterial populations present in the gut and relatively low numbers of the bacterial genus Bifidobacterium in the healthy adult $(<5 \%)$ [29] this genus is most often targeted by prebiotics. This is because of it's association with multiple health benefits, including reducing the proliferation of colorectal cancer and the concentration of circulating cholesterol [30, 31]. A decrease Bifidobacterium levels below those in healthy adults has been linked to disorders such as antibiotic-associated diarrhoea, inflammatory bowel disease, irritable bowel syndrome, obesity and allergies [32] demonstrating their importance in the colon despite relatively low numbers. In this study, all substrates demonstrated beneficial effects by significantly increasing $(p<0.05)$ the populations of Bifidobacterium from 8 to $24 \mathrm{~h}$ compared to the negative control (Table 2; Fig. 3). Unlike the FOS and AGP + AX mixture which showed the maximum Bifidobacterium growth at $8 \mathrm{~h}$, proliferation was slower with AGP and AX singly as substrates, reaching the greatest population numbers after $24 \mathrm{~h}$. This effect was observed with all donors in the study; therefore, it appears to show that bifidobacteria ferment soluble wheat flour AX and AGP more slowly than FOS. The same effect was observed with the populations of the predominant beneficial bacterial group [33] Clostridium coccoides/Eubacterium rectale (Clostridium Cluster XIVa 

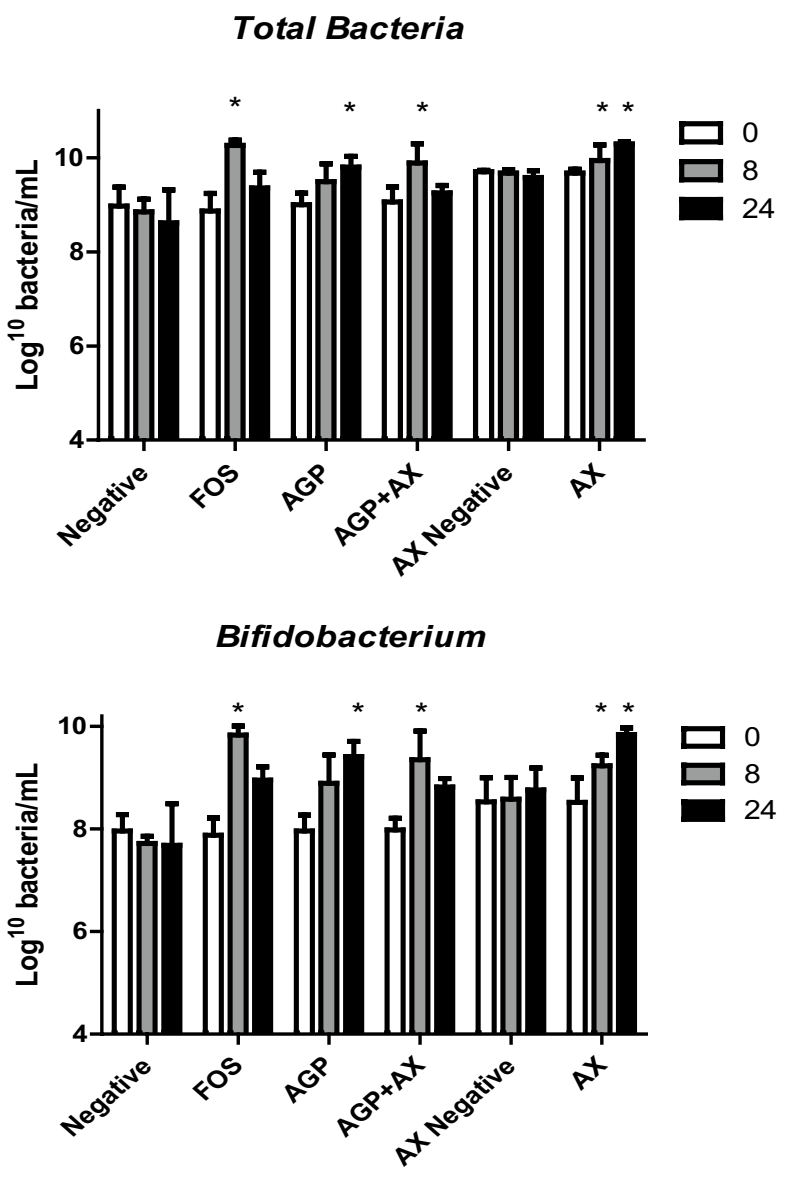

Clostridium coccoides / Eubacterium rectale

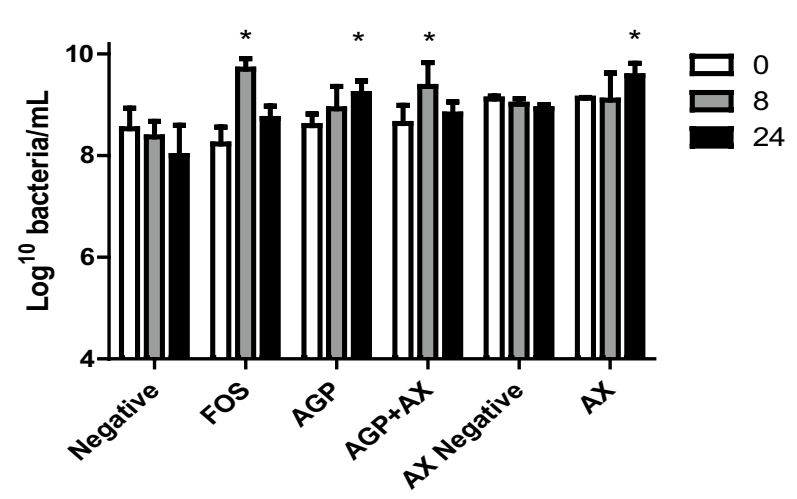

Fig. 3 Total bacteria, Bifidobacterium and Clostridium coccoides/ Eubacterium rectale populations after fermentation of different substrates at times 0,8 , and $24 \mathrm{~h}$ analysed by Flow-FISH. Error bars show SEM $(n=3)$. Significant differences $(p<0.05)$ from negative control are denoted with asterisk

and XIVb), which showed significant increases simultaneously with bifidogenic effects and may be indicative of cross feeding interactions as reported by Rivière et al. [32].

The structures of fermentable carbohydrates, including the degree of polymerisation (DP) and molecular weight have previously been shown to affect the rate of fermentation [26] and FOS is thought to be rapidly fermented due to its low DP [34]. In this study, the DP of the AX (average DP 131) was much greater than that of FOS (DP 2-8). The longer polysaccharides in AX have fewer non-reducing ends per unit mass than FOS, providing less substrate for hydrolysis by bacterial enzymes, which may have contributed to the slower rate of fermentation shown with AX. Wheat AGP is considered have three carbohydrate moieties. Their molecular masses have not been determined but estimates of between 122 and 389 sugar residues can be made based on the reported mass of the whole AGP molecule, ranging from 22,000 to 70,000 [4,35-37]. This mass is much greater than that of FOS, accounting for the slower fermentation.

A slower rate can be advantageous for health as it allows the prebiotic to reach the more distal regions of the colon, where the levels of fermentable carbohydrate are lower, and fermentation of proteins occurs with adverse effects [38].

The combination of AX + AGP showed faster fermentation than either substrate singly, with significant increases in beneficial bacterial populations by $8 \mathrm{~h}$ fermentation, similar to that of FOS.

It is possible that a faster fermentation may be achieved via utilization of multiple non-competing bacterial enzymes. For example, some Bacteroides spp. have been found to fully ferment highly branched xylans as well as $\beta 1-3$ and $\beta 1-4$ arabinogalactans from soy by producing multiple enzymes [39].

Desulfovibrionales (DSV) is a group of sulphate-reducing bacteria which are suggested to contribute to the development of ulcerative colitis through the production of cytotoxic $\mathrm{H}_{2} \mathrm{~S}$ and add to the pathology of the disease [40, 41] (although this role is disputed as analyses of bacterial populations from faeces and mucosal biopsies have so far failed to demonstrate changes in DSV populations associated with the disease) [42]. Similarly, bacteria of Clostridium cluster I and $I I$ are also considered to have adverse effects on health, as they are associated with protein fermentation and some end products of protein fermentation can be harmful to the host, e.g., amines and ammonia [43]. A shift to protein fermentation has been linked with increases in diseases such as irritable bowel syndrome (IBS) and colonic cancers, which occur more often in the distal regions of the gut $[43,44]$. The populations of Desulfovibrionales, and Clostridium-cluster I and II did not increase with any of the substrates, despite the presence of a peptide chain in the AGP. This could be due to competition from saccharolytic bacteria which were still increasing up to $24 \mathrm{~h}$ of fermentation, to the low proportion of the peptide in the AGP structure 8\% [45] or to the inaccessibility of the peptide, surrounded by arabinogalactan [45].

Total SCFA concentrations were highest with the positive control (FOS) after $24 \mathrm{~h}$ and comprised mostly acetate. The second highest concentration of total SCFAs was generated 
by $\mathrm{AGP}+\mathrm{AX}$ combined, being higher than those resulting from fermentation of either single component and comprised mainly acetate and propionate. The most abundant SCFAs, acetate, propionate and butyrate, have been shown to have multiple beneficial effects for the host, for example, by providing dietary energy, and by suppressing the growth of pathogens by decreasing the $\mathrm{pH}$ of the intestinal lumen [46]. These SCFAs were also reported to have anti-inflammatory effects in rats [47] and influence intestinal motility in rats via G-protein coupled receptor activation, with acetate being the most effective, followed by propionate and butyrate [48]. The production pathways of acetate are found widely among bacterial groups, however, pathways for production of propionate, butyrate, and lactate appear more highly conserved and substrate specific [49].

Large increases in acetate were observed after fermentation of all substrates, with AGP and AGP + AX showing the greatest increases. Bifidobacteria are known to produce acetate $[50,51]$ and were observed to increase concomitantly with acetate concentration with all substrates, however, (as Actinobacteria) they are present in much smaller numbers than bacteria from the Bacteroides and Firmicutes phyla. Acetate production occurs via widely distributed pathways among bacterial groups so the increases in acetate can also be attributed to other bacteria, including the predominant group found in the gut which can also produce acetate, the Clostridium coccoides group [33, 52] which increased in all substrates. Pathways for propionate, butyrate and lactate production appear more highly conserved and substrate specific [49]. The decreases in lactate observed during fermentation of AGP, AGP + AX and AX demonstrate a healthy colonic environment and bacterial cross feeding. Under healthy gut conditions lactate is only present in low concentrations in faeces $(<5 \mathrm{mM})$ [53] because bacterial breakdown markedly exceeds production [54]. Lactate is formed from pyruvate through the action of lactate dehydrogenase in the homofermentative pathway by many common gut bacteria including Lactobacillus, Bifidobacterium, Enterococcus, and Streptococcus and Eubacterium spp. [55], but can also be converted to other SCFA. Decreases in lactate can, therefore, represent cross-feeding of different bacterial species including the species Roseburia intestinalis, Eubacterium rectale, Eubacterium halii, and Anaerostipes caccae [53, $54,56,57]$ which utilise lactate for production of other SCFAs-mainly butyrate, but also propionate and valerate [56]. Because this mechanism is widely utilised it is not possible to attribute the decreases in lactate to specific bacterial groups in this study, however, the large decreases in lactate shown by fermentation of both AGP and AGP + AX demonstrates a greater proportion of lactate-utilizing than lactateproducing bacteria which is important as an accumulation of lactate in the gut can cause acidosis, neurotoxicity, and cardiac arrhythmia [58]. Lactate levels were not observed to drop over time with fermentation of FOS, which remained similar to the negative control, however, this was due to large individual variations (Table $\mathrm{S} 1$ ).

Butyrate is produced by a range of bacteria, including the Clostridium, Roseburia and Eubacterium genera [51] but is dominated by Faecalibacterium prausnitzii, Eubacterium rectale, Eubacterium hallii and $R$. bromii [56]. No significant increases in butyrate were observed with fermentation of any of the substrates in this study (although FOS gave a non-significant increase by $24 \mathrm{~h}$ ). It is thought that wheat polysaccharides, which would include, AX and AGP, are not directly butyrogenic, but rely on cross-feeding interactions between bacteria that utilize metabolites to produce butyrate and those producing the precursor metabolites directly from fermentation (e.g., Eubacterium spp., Faecalibacterium prausnitzii, and Roseburia which can utilize acetate from bifidobacteria) [58]. The butyrate concentration has previously been shown to increase during in vitro fermentation of several commercially available samples of wheat AX [23], however, this effect was not observed in this study and may be due to a lack of the dominant butyrate producers Faecalibacterium prausnitzii [56], which did not increase during fermentation.

Wheat AGP showed potential prebiotic activity during in vitro fermentation, by selectively increasing populations of beneficial bacteria including Bifidobacterium and Eubacterium genera and providing increases in the concentration of SCFAs (mainly consisting of acetate). A slower fermentation can demonstrate that a substrate is able to persist to more distal regions of the colon. AGP showed slower bacterial fermentation than FOS, however, this persistence is unlikely to occur when wheat products are consumed as combining AGP with AX resulted in faster utilisation of the substrates. Since the ratio of water-soluble AX to AGP used in these experiments is similar to that in white wheat flour, their potential to act synergistically is more relevant to the consumption of wheat products than the results obtained with single substrates. This study used faecal samples to provide microbial populations for fermentation in vitro. The results should, therefore, be confirmed with larger numbers of samples and an in vivo human intervention study to further clarify the role of AGP/AGP + AX in colonic fermentation.

Acknowledgements This research was supported by the funding was obtained from the Biotechnology and Biological Sciences Research Council (BBSRC), Lawes Agricultural Trust and the University of Reading.

\section{Compliance with ethical standards}

Conflict of interest The manuscript does not contain clinical studies or patient data. On behalf of all authors, the corresponding author states that there is no conflict of interest. 
OpenAccess This article is distributed under the terms of the Creative Commons Attribution 4.0 International License (http://creativeco mmons.org/licenses/by/4.0/), which permits unrestricted use, distribution, and reproduction in any medium, provided you give appropriate credit to the original author(s) and the source, provide a link to the Creative Commons license, and indicate if changes were made.

\section{References}

1. JMares D, Stone B (1973) Studies on wheat endosperm I. Chemical composition and ultrastructure of the cell walls. Aust J Biol Sci 26:793. https://doi.org/10.1071/BI9730793

2. Huynh B-L, Palmer L, Mather DE, Wallwork H, Graham RD, Welch RM, Stangoulis JCR (2008) Genotypic variation in wheat grain fructan content revealed by a simplified HPLC method. J Cereal Sci 48:369-378. https://doi.org/10.1016/j.jcs.2007.10.004

3. Loosveld A-MA, Grobet PJ, Delcour JA (1997) Contents and structural features of water-extractable arabinogalactan in wheat flour fractions. J Agric Food Chem 45:1998-2002. https://doi. org/10.1021/jf960901k

4. Loosveld A, Maes C, van Casteren WHM, Schols HA, Grobet PJ, Delcour JA (1998) Structural Variation and levels of waterextractable arabinogalactan-peptide in European wheat flours. Cereal Chem J 75:815-819. https://doi.org/10.1094/CCHEM .1998.75.6.815

5. Van den Bulck K, Loosveld A-MA, Courtin CM, Proost P, Van Damme J, Robben J, Mort A, Delcour JA (2002) Amino acid sequence of wheat flour arabinogalactan-peptide, identical to part of grain softness protein GSP-1, leads to improved structural model. Cereal Chem J 79:329-331. https://doi. org/10.1094/CCHEM.2002.79.3.329

6. Tryfona T, Liang H-C, Kotake T, Kaneko S, Marsh J, Ichinose H, Lovegrove A, Tsumuraya Y, Shewry PR, Stephens E, Dupree P (2010) Carbohydrate structural analysis of wheat flour arabinogalactan protein. Carbohydr Res 345:2648-2656. https://doi. org/10.1016/j.carres.2010.09.018

7. Wilkinson MD, Tosi P, Lovegrove A, Corol DI, Ward JL, Palmer R, Powers S, Passmore D, Webster G, Marcus SE (2017) The Gsp-1 genes encode the wheat arabinogalactan peptide. J Cereal Sci 74:155-164

8. Gibson GR, Hutkins R, Sanders ME, Prescott SL, Reimer RA, Salminen SJ, Scott K, Stanton C, Swanson KS, Cani PD, Verbeke K, Reid G (2017) Expert consensus document: the International Scientific Association for Probiotics and Prebiotics (ISAPP) Consensus statement on the definition and scope of prebiotics. Nat Rev Gastroenterol Hepatol. https://doi. org/10.1038/nrgastro.2017.75

9. Gibson GR, Roberfroid MB (1995) Dietary modulation of the human colonic microbiota: introducing the concept of prebiotics. J Nutr 125:1401-1412

10. Kolida S, Gibson GR (2007) Prebiotic capacity of inulin-type fructans. J Nutr 137:2503S-2506S. https://doi.org/10.1093/ jn/137.11.2503S

11. Broekaert WF, Courtin CM, Verbeke K, Van de Wiele T, Verstraete W, Delcour JA (2011) Prebiotic and other health-related effects of cereal-derived arabinoxylans, arabinoxylan-oligosaccharides, and xylooligosaccharides. Crit Rev Food Sci Nutr 51:178-194. https://doi.org/10.1080/10408390903044768

12. Carlson JL, Erickson JM, Hess JM, Gould TJ, Slavin JL (2017) Prebiotic dietary fiber and gut health: comparing the in vitro fermentations of beta-glucan, inulin and xylooligosaccharide. Nutrients 9:1361. https://doi.org/10.3390/nu9121361
13. Hughes SA, Shewry PR, Gibson GR, McCleary BV, Rastall RA (2008) In vitro fermentation of oat and barley derived $\beta$-glucans by human faecal microbiota: in vitro fermentation of cereal $\beta$-glucans. FEMS Microbiol Ecol 64:482-493. https://doi.org /10.1111/j.1574-6941.2008.00478.x

14. Marsh JT, Tryfona T, Powers SJ, Stephens E, Dupree P, Shewry PR, Lovegrove A (2011) Determination of the $N$-glycosylation patterns of seed proteins: applications to determine the authenticity and substantial equivalence of genetically modified (GM) crops. J Agric Food Chem 59:8779-8788. https://doi. org/10.1021/jf2010854

15. Rycroft CE, Jones MR, Gibson GR, Rastall RA (2001) A comparative in vitro evaluation of the fermentation properties of prebiotic oligosaccharides. J Appl Microbiol 91:878-887. https ://doi.org/10.1046/j.1365-2672.2001.01446.x

16. Rycroft CE, Jones MR, Gibson GR, Rastall RA (2001) Fermentation properties of gentio-oligosaccharides. Lett Appl Microbiol 32:156-161. https://doi.org/10.1046/j.1472765x.2001.00875.x

17. Langendijk PS, Schut F, Jansen GJ, Raangs GC, Kamphuis GR, Wilkinson MH, Welling GW (1995) Quantitative fluorescence in situ hybridization of Bifidobacterium spp. with genus-specific 16S RRNA-targeted probes and its application in fecal samples. Appl Environ Microbiol 61:3069-3075

18. Manz W, Amann R, Ludwig W, Vancanneyt M, Schleifer K-H (1996) Application of a suite of 16S RRNA-specific oligonucleotide probes designed to investigate bacteria of the phylum cytophaga-flavobacter-bacteroides in the natural environment. Microbiology 142:1097-1106

19. Harmsen HJM, Elfferich P, Schut F, Welling GW (1999) A 16S RRNA-targeted probe for detection of lactobacilli and enterococci in faecal samples by fluorescent in situ hybridization. Microb Ecol Health Dis. https://doi.org/10.3402/mehd.v11i1.7876

20. Harmsen HJM, Wildeboer-Veloo ACM, Grijpstra J, Knol J, Degener JE, Welling GW (2000) Development of 16S RRNAbased probes for the coriobacterium group and the atopobium cluster and their application for enumeration of coriobacteriaceae in human feces from volunteers of different age groups. Appl Environ Microbiol 66:4523-4527. https://doi.org/10.1128/ AEM.66.10.4523-4527.2000

21. Walker AW, Duncan SH, McWilliam Leitch EC, Child MW, Flint $\mathrm{HJ}$ (2005) PH and peptide supply can radically alter bacterial populations and short-chain fatty acid ratios within microbial communities from the human colon. Appl Environ Microbiol 71:36923700. https://doi.org/10.1128/AEM.71.7.3692-3700.2005

22. Franks AH, Harmsen HJ, Raangs GC, Jansen GJ, Schut F, Welling GW (1998) Variations of bacterial populations in human feces measured by fluorescent in situ hybridization with group-specific 16S RRNA-targeted oligonucleotide probes. Appl Environ Microbiol 64:3336-3345

23. Hold GL, Schwiertz A, Aminov RI, Blaut M, Flint HJ (2003) Oligonucleotide probes that detect quantitatively significant groups of butyrate-producing bacteria in human feces. Appl Environ Microbiol 69:4320-4324. https://doi.org/10.1128/ AEM.69.7.4320-4324.2003

24. Ciucanu I, Kerek F (1984) A simple and rapid method for the permethylation of carbohydrates. Carbohydr Res 131:209-217. https://doi.org/10.1016/0008-6215(84)85242-8

25. Snart J, Bibiloni R, Grayson T, Lay C, Zhang H, Allison GE, Laverdiere JK, Temelli F, Vasanthan T, Bell R, Tannock GW (2006) Supplementation of the diet with high-viscosity betaglucan results in enrichment for lactobacilli in the rat cecum. Appl Environ Microbiol 72:1925-1931. https://doi.org/10.1128/ AEM.72.3.1925-1931.2006

26. Hughes SA, Shewry PR, Li L, Gibson GR, Sanz ML, Rastall RA (2007) In vitro fermentation by human fecal microflora of wheat 
arabinoxylans. J Agric Food Chem 55:4589-4595. https://doi. org/10.1021/jf070293g

27. Cummings JH (1981) Short chain fatty acids in the human colon. Gut 22:763

28. Cummings JH, Macfarlane GT (1997) Colonic microflora: nutrition and health. Nutrition 13:476-478

29. Arumugam M, Raes J, Pelletier E, Le Paslier D, Yamada T, Mende DR, Fernandes GR, Tap J, Bruls T, Batto J-M, Bertalan M, Borruel N, Casellas F, Fernandez L, Gautier L, Hansen T, Hattori M, Hayashi T, Kleerebezem M, Kurokawa K, Leclerc M, Levenez F, Manichanh C, Nielsen HB, Nielsen T, Pons N, Poulain J, Qin J, Sicheritz-Ponten T, Tims S, Torrents D, Ugarte E, Zoetendal EG, Wang J, Guarner F, Pedersen O, de Vos WM, Brunak S, Doré J, Antolín M, Artiguenave F, Blottiere HM, Almeida M, Brechot C, Cara C, Chervaux C, Cultrone A, Delorme C, Denariaz G, Dervyn R, Foerstner KU, Friss C, van de Guchte M, Guedon E, Haimet F, Huber W, van Hylckama-Vlieg J, Jamet A, Juste C, Kaci G, Knol J, Lakhdari O, Layec S, Le Roux K, Maguin E, Mérieux A, Melo Minardi R, M'rini C, Muller J, Oozeer R, Parkhill J, Renault P, Rescigno M, Sanchez N, Sunagawa S, Torrejon A, Turner K, Vandemeulebrouck G, Varela E, Winogradsky Y, Zeller G, Weissenbach J, Ehrlich SD, Bork P (2011) Enterotypes of the human gut microbiome. Nature 473:174-180. https://doi.org/10.1038/ nature09944

30. Singh J, Rivenson A, Tomita M, Shimamura S, Ishibashi N, Reddy BS (1997) Bifidobacterium longum, a lactic acid-producing intestinal bacterium inhibits colon cancer and modulates the intermediate biomarkers of colon carcinogenesis. Carcinogenesis 18:833-841

31. Zanotti I, Turroni F, Piemontese A, Mancabelli L, Milani C, Viappiani A, Prevedini G, Sanchez B, Margolles A, Elviri L (2015) Evidence for cholesterol-lowering activity by Bifidobacterium bifidum PRL2010 through gut microbiota modulation. Appl Microbiol Biotechnol 99:6813-6829

32. Rivière A, Selak M, Lantin D, Leroy F, De Vuyst L (2016) Bifidobacteria and butyrate-producing colon bacteria: importance and strategies for their stimulation in the human gut. Front Microbiol. https://doi.org/10.3389/fmicb.2016.00979

33. Kurakawa T, Ogata K, Matsuda K, Tsuji H, Kubota H, Takada T, Kado Y, Asahara T, Takahashi T, Nomoto K (2015) Diversity of intestinal clostridium coccoides group in the Japanese population, as demonstrated by reverse transcription-quantitative PCR. Popoff, M.R., Ed. PLoS One 10:e0126226. https://doi. org/10.1371/journal.pone.0126226

34. Stewart ML, Timm DA, Slavin JL (2008) Fructooligosaccharides exhibit more rapid fermentation than long-chain inulin in an in vitro fermentation system. Nutrition Research 28:329-334

35. Fincher GB, Sawyer WH, Stone BA (1974) Chemical and physical properties of an arabinogalactan-peptide from wheat endosperm. Biochem J 139:535-545. https://doi.org/10.1042/ bj1390535

36. Izydorczyk M, Biliaderis CG, Bushuk W (1991) Comparison of the structure and composition of water-soluble pentosans from different wheat varieties. Cereal Chem 68:139-144

37. Van den Bulck K, Swennen K, Loosveld A-MA, Courtin CM, Brijs K, Proost P, Van Damme J, Van Campenhout S, Mort A, Delcour JA (2005) Isolation of cereal arabinogalactan-peptides and structural comparison of their carbohydrate and peptide moieties. J Cereal Sci 41:59-67

38. Macfarlane GT, Gibson GR, Cummings JH (1992) Comparison of fermentation reactions in different regions of the human colon. J Appl Bacteriol 72:57-64

39. Van Laere KMJ, Hartemink R, Bosveld M, Schols HA, Voragen AGJ (2000) Fermentation of plant cell wall derived polysaccharides and their corresponding oligosaccharides by intestinal bacteria. J Agric Food Chem 48:1644-1652. https:// doi.org/10.1021/jf990519i

40. Khalil NA, Walton GE, Gibson GR, Tuohy KM, Andrews SC (2014) In vitro batch cultures of gut microbiota from healthy and ulcerative colitis (UC) subjects suggest that sulphate-reducing bacteria levels are raised in UC and by a protein-rich diet. Int J Food Sci Nutr 65:79-88. https://doi.org/10.3109/09637 486.2013.825700

41. Coutinho CMLM, Coutinho-Silva R, Zinkevich V, Pearce CB, Ojcius DM, Beech I (2017) Sulphate-reducing bacteria from ulcerative colitis patients induce apoptosis of gastrointestinal epithelial cells. Microb Pathog 112:126-134

42. Rowan FE, Docherty NG, Coffey JC, O'Connell PR (2009) Sulphate-reducing bacteria and hydrogen sulphide in the aetiology of ulcerative colitis. Br J Surg 96:151-158. https://doi. org/10.1002/bjs.6454

43. Windey K, De Preter V, Verbeke K (2012) Relevance of protein fermentation to gut health. Mol Nutr Food Res 56:184-196. https://doi.org/10.1002/mnfr.201100542

44. Roberfroid M, Gibson GR, Hoyles L, McCartney AL, Rastall R, Rowland I, Wolvers D, Watzl B, Szajewska H, Stahl B, Guarner F, Respondek F, Whelan K, Coxam V, Davicco M-J, Léotoing L, Wittrant Y, Delzenne NM, Cani PD, Neyrinck AM, Meheust A (2010) Prebiotic effects: metabolic and health benefits. Br J Nutr 104:S1-S63. https://doi.org/10.1017/S0007114510003363

45. Fincher GB, Stone BA (1974) A water-soluble arabinogalactanpeptide from wheat endosperm. Aust J Biol Sci 27:117-132

46. Blaut M (2002) Relationship of prebiotics and food to intestinal microflora. Eur J Nutr 41:i11-i16

47. Vinolo MAR, Rodrigues HG, Nachbar RT, Curi R (2011) Regulation of inflammation by short chain fatty acids. Nutrients 3:858 876. https://doi.org/10.3390/nu3100858

48. Dass NB, John AK, Bassil AK, Crumbley CW, Shehee WR, Maurio FP, Moore GBT, Taylor CM, Sanger GJ (2007) The relationship between the effects of short-chain fatty acids on intestinal motility in vitro and GPR43 receptor activation. Neurogastroenterol Motil 19:66-74

49. Morrison DJ, Preston T (2016) Formation of short chain fatty acids by the gut microbiota and their impact on human metabolism. Gut Microbes 7:189-200. https://doi.org/10.1080/19490 976.2015.1134082

50. Fukuda S, Toh H, Hase K, Oshima K, Nakanishi Y, Yoshimura K, Tobe T, Clarke JM, Topping DL, Suzuki T, Taylor TD, Itoh K, Kikuchi J, Morita H, Hattori M, Ohno H (2011) Bifidobacteria can protect from enteropathogenic infection through production of acetate. Nature 469:543-547. https://doi.org/10.1038/nature0964 6

51. Bindels LB, Delzenne NM, Cani PD, Walter J (2015) Towards a more comprehensive concept for prebiotics. Nat Rev Gastroenterol Hepatol 12:303

52. Kamlage B, Gruhl R, Blaut M (1997) Isolation and characterization of two new homoacetogenic hydrogen-utilizing bacteria from the human intestinal tract that are closely related to clostridium coccoides. Appl Environ Microbiol 63:7

53. Duncan SH, Louis P, Flint HJ (2004) Lactate-utilizing bacteria, isolated from human feces, that produce butyrate as a major fermentation product. Appl Environ Microbiol 70:5810-5817. https ://doi.org/10.1128/AEM.70.10.5810-5817.2004

54. Belenguer A, Holtrop G, Duncan SH, Anderson SE, Calder AG, Flint HJ, Lobley GE (2011) Rates of production and utilization of lactate by microbial communities from the human colon. FEMS Microbiol Ecol 77:107-119

55. Barcenilla A, Pryde SE, Martin JC, Duncan SH, Stewart CS, Henderson C, Flint HJ (2000) Phylogenetic relationships of butyrateproducing bacteria from the human gut. Appl Environ Microbiol 66:1654-1661 
56. Bourriaud C, Robins RJ, Martin L, Kozlowski F, Tenailleau $\mathrm{E}$, Cherbut C, Michel C (2005) Lactate is mainly fermented to butyrate by human intestinal microfloras but inter-individual variation is evident. J Appl Microbiol 99:201-212. https://doi.org/10. 1111/j.1365-2672.2005.02605.x

57. Louis P, Young P, Holtrop G, Flint HJ (2010) Diversity of human colonic butyrate-producing bacteria revealed by analysis of the
butyryl-CoA:acetate CoA-transferase gene. Environ Microbiol 12:304-314. https://doi.org/10.1111/j.1462-2920.2009.02066.x

58. Pham VT, Lacroix C, Braegger CP, Chassard C (2017) Lactateutilizing community is associated with gut microbiota dysbiosis in colicky infants. Sci Rep. https://doi.org/10.1038/s41598-01711509-1 